\title{
Impact of nanotechnology in cancer: emphasis on nanochemoprevention
}

\author{
This article was published in the following Dove Press journal: \\ International Journal of Nanomedicine \\ I February 2012 \\ Number of times this article has been viewed
}

\section{Imtiaz A Siddiqui \\ Vaqar M Adhami \\ Jean Christopher \\ Chamcheu \\ Hasan Mukhtar}

Department of Dermatology,

University of Wisconsin,

Madison, WI, USA
Correspondence: Hasan Mukhtar

Department of Dermatology,

University of Wisconsin, Medical Sciences

Center B-25, 1300 University Avenue,

Madison, WI-53706, USA

Tel +l 6082633927

Fax + I 6082635223

Email hmukhtar@wisc.edu

\begin{abstract}
Since its advent in the field of cancer, nanotechnology has provided researchers with expertise to explore new avenues for diagnosis, prevention, and treatment of the disease. Utilization of nanotechnology has enabled the development of devices in nanometer ( $\mathrm{nm}$ ) sizes which could be designed to encapsulate useful agents that have shown excellent results but otherwise are generally toxic due to the doses intended for extended use. In addition, examples are also available where these devices are easily conjugated with several purposeful moieties for better localization and targeted delivery. We introduced a novel concept in which nanotechnology was utilized for enhancing the outcome of chemoprevention. This idea, which we termed as "nanochemoprevention," was subsequently exploited by several laboratories worldwide and has now become an advancing field in chemoprevention research. This review examines some of the up and coming applications of nanotechnology for cancer detection, imaging, treatment, and prevention. Further, we detail the current and future utilization of nanochemoprevention for prevention and treatment of cancer.
\end{abstract}

Keywords: nanochemoprevention, cancer, nanotechnology

\section{Introduction}

Nanotechnology is the study of materials on atomic and molecular scales that generally deal with arrangements in the nano $\left(10^{-9}\right)$ size range, and involves developing materials or devices within that framework. The basic rationale behind nanotechnology is that metals, semiconductors, and polymeric particles demonstrate novel optical, electronic, magnetic, and structural properties that are frequently not accessible from individual molecules and bulk solids. ${ }^{1,2}$ This field is an emerging multidisciplinary arena that employs techniques and tools from diverse disciplines, eg, biology, engineering, chemistry, and medicine compiled together to achieve a common objective. Because most biological processes, including those that are cancer-related, occur in the nanoscale, nanoparticulate technology has been greatly appreciated as a potential tool for cancer diagnosis and treatment, a field of science that is generally referred as "cancer nanotechnology." This scientific discipline seeks to describe the relationships between devices that are nanoscale and cellular and molecular components specifically related to cancer.

Cancer nanotechnology has been aggressively evaluated and implemented in cancer management and therapeutics, with suggestions that it might lead to major advances in diagnosis, detection, and treatment of the disease. ${ }^{1,3-6}$ It offers many potential benefits in cancer research ranging from, but not limited to, passive and active targeting, increased solubility/bioavailability, and novel therapies. ${ }^{7}$ Nanotechnology currently is 
being evaluated in cancer in two broad areas of nanovectors, ie, nanoparticles which can be loaded with drugs or imaging agents and then targeted to tumors, and high throughput nanosensor devices for detecting the biological signatures of cancer. Cancer nanotechnology is considered to have great potential due to the ability to engineer devices with unique therapeutic properties that because of their small size can infiltrate tumors deeply with a high level of specificity. This area of research is highly acknowledged, even by the National Cancer Institute, which considers that nanotechnology offers an extraordinary paradigm-shifting opportunity to make significant advances in cancer diagnosis and treatment. ${ }^{5}$

\section{Nanotechnology in medicine}

An interdisciplinary field known as "nanomedicine" has gradually evolved from the merger of medicine and nanotechnology, and has established great possibilities against several diseases in the human population. Overall, nanomedicine is the process of diagnosing, treating, and preventing disease and traumatic injury, of relieving pain, and of preserving and improving human health, using molecular tools and molecular knowledge of the human body. ${ }^{8,9}$ Currently nanomedicine is being utilized in wide ranging arenas, and these applications have a potential to revolutionize the way we detect and treat damage to the human body and diseases in the future.

Although several of these techniques were imaginatively speculated on only a few years ago, they are rapidly making remarkable progress towards overcoming translational certainties. Nanotechnology has been exploited for over one hundred diverse techniques. ${ }^{8}$ However, we will briefly focus on a selected few most interesting emerging advances and diverse research categories that are very near to accomplishment, and their likely incorporation into valuable medical diagnostics or clinical therapeutics by focusing on cancer.

\section{Liposomes}

Liposomes are artificially prepared vesicles made of a lipid bilayer that can be filled with drugs and used to deliver drugs for cancer and other diseases. These have become very resourceful in biology and medicine because of their enormous diversity of structure and compositions. ${ }^{6,10-12}$ An interesting property of liposomes is their natural ability to target cancer. The endothelial wall of all healthy human blood vessels is encapsulated by endothelial cells that are bound together by tight junctions that stop large particles in the blood from leaking out of the vessel. Tumor vessels do not harbor the same level of seal between cells and are diagnostically leaky. This ability is known as the enhanced permeability and retention effect. Liposomes of certain sizes, typically less than $200 \mathrm{~nm}$, can rapidly enter tumor sites from the blood, but are kept in the bloodstream by the endothelial wall in healthy tissue vasculature. ${ }^{6,13}$

Currently, liposome delivery systems are being utilized for anticancer drugs such as Doxil ${ }^{\circledR},{ }^{14,15}$ DaunoXome $^{\circledR},{ }^{16,17}$ DepoCyt ${ }^{\circledR},{ }^{18,19}$ and ONCO-TCS, ${ }^{20}$ which are liposomal formulations of doxorubicin, daunorubicin, cytarabine, and vincristine, respectively. In humans, polyethylene glycol (PEG)ylated liposomal drugs have been demonstrated to achieve prolonged circulation with a terminal half-life of 55 hours. ${ }^{4,6,21}$ Several laboratories have used an approach of packaging therapeutic molecules inside liposomes and decorating the surface using "Trojan horse" technology with promising results. ${ }^{11,22,23}$ Leamon et $\mathrm{al}^{24}$ evaluated the in vitro and in vivo status of the delivery of oligonucleotides encapsulated in folate-coated liposomes. This study suggested that folate liposomes can effectively deliver oligonucleotides into folate receptor-bearing cells in vitro, but failed to demonstrate efficacy in vivo, and the targeted liposomes accumulated poorly in KB tumor tissue. ${ }^{24}$ Liposomes enable the intracellular release of many macromolecules including protein toxins, gene therapy vectors, and oligonucleotides, into cancer cells in addition to the delivery of suitable concentration of drugs to the target tumor cell surface. ${ }^{25}$

The majority of studies demonstrate that liposomal formulations of anticancer drugs are usually less toxic than the nonencapsulated formulations, but there is some evidence showing some liposome-specific adverse effects. These effects are limited to hypersensitivity reactions and skin reactions. ${ }^{26}$ Chen et al observed hypersensitivity associated with infusion of liposomal doxorubicin in one ovarian cancer patient. ${ }^{27}$ Hypersensitivity reactions to liposomal formulations are very uncommon, but hemodynamic, respiratory, cutaneous and subjective manifestations include hypotension or hypertension, dyspnea, flushing, rash, and a feeling of choking has been seen in up to $30.8 \%$ of the patients. ${ }^{28-31}$ These hypersensitivity reactions are easily controlled by slowing of the rate, or stopping the infusion, and standard measures of anaphylaxis prevention and treatment also usually seem to be sufficiently effective.

\section{Quantum dots}

In recent years, semiconductor quantum dots have attracted the attention of many research groups owing to their scientific and technological significance in microelectronics, 
optoelectronics, and cellular imaging. These semiconductor nanocrystals have broad potential for use in various applications in the management and treatment of cancer. ${ }^{32-34}$ These are very effective because the broad absorption and narrow emission characteristics of the quantum dots make it possible to perform multicolor imaging with a single excitation source. The high fluorescence quantum yield of the quantum dots, their resistance to photobleaching, and their unique properties make them good candidates for fluorescent tagging for in vivo molecular and cellular imaging. ${ }^{35-38}$ Quantum dots also provide a versatile nanoscale scaffold for designing multifunctional nanoparticles with both imaging and therapeutic functions. Nie et $\mathrm{al}^{1}$ for the first time reported that it is feasible to target and image prostate tumors simultaneously in living animal models using bioconjugated, prostate membrane antigen-targeted quantum dots. The surface of quantum dots can be engineered or modified to improve quantum dot solubility, sensitivity, specificity, and visualization in target tissue. However, because of their composition of heavy metals and a few reports of cytotoxicity, quantum dots have been the subject of toxicological scrutiny. Quantum dot toxicity depends on multiple factors derived from both inherent physicochemical properties and environmental conditions. Some in vitro studies have indicated that quantum dots may be toxic, and most of the toxicity could be attributed to surface coating. ${ }^{39-41}$ A subsequent study demonstrated that quantum dot toxicity was reduced after surface modification with $\mathrm{N}$-acetylcysteine, while the nonmodified quantum dots induced lipid peroxidation in the cells. ${ }^{42}$ The issue of toxicity has been studied by several groups who have reported that the release of toxic metals might be limited with biocompatible surface coatings, such as PEG or micelle encapsulation. ${ }^{43-45}$

\section{Polymeric micelles}

A micelle is defined as a collection of amphiphilic surfactant molecules; micelles are turning out to be a keystone in the future of therapeutics. ${ }^{46}$ The first polymeric micelle formulation of paclitaxel, Genexol-PM (PEG-poly (d,l-lactide)-paclitaxel), was Cremophor-EL-free polymeric micelle-formulated paclitaxel. ${ }^{47,48} \mathrm{~A}$ Phase I and pharmacokinetic study has been conducted in patients with advanced refractory malignancies. Several polymeric PEG-micelle formulations have entered clinical trials, eg, a doxorubicin-loaded polymeric micelle has gone through a Phase I clinical trial for solid tumors and shown encouraging results in treating restenosis by accumulation in vascular lesions. ${ }^{49,50}$ Torchilin et $\mathrm{al}^{51}$ have formulated antitumor antibody-conjugated polymeric micelles (immunomicelles), encapsulating the water-insoluble drug, paclitaxel, that effectively recognize and bind to various cancer cells in vitro. Mohanty et $\mathrm{al}^{52}$ have developed curcumin-loaded methoxy PEG/poly- $\varepsilon$-caprolactone diblock copolymeric micelles, and have shown improved efficacy of the micellar system over the native drug using pancreatic cancer cell lines. Utilization of micelles for cancer therapy is limited due to several factors, most importantly by the fact that these micelles allow the encapsulated drug to be released prematurely. However, most of these limitations can be easily overcome by the correct chemistry during preparation of the micelles.

\section{Nanocantilever}

Microarray methods involving the detection of specific biomolecular interactions are now an indispensable tool for disease diagnosis, genome research, and drug discovery. Tiny bars anchored at one end can be engineered to bind to molecules associated with cancer. These molecules can bind to altered DNA and proteins that are present in certain types of cancer. During detection procedures, when biospecific interactions occur between a receptor immobilized on one side of a cantilever and a ligand in solution, the cantilever bends; if detected optically, it is possible to tell whether cancer molecules are present and, hence, detect early molecular events in the development of cancer. Deflection of the silicon beams depends on the amount of DNA or protein bound to the cantilever surface. The deflection can be observed directly, using laser light, or by measurement of perturbations in their resonant vibration frequency. $\mathrm{Wu}$ et $\mathrm{al}^{53}$ used microcantilevers to detect single-nucleotide polymorphisms in a 10-mer DNA target oligonucleotide without the use of extrinsic fluorescent or radioactive labeling. They also demonstrated the applicability of microcantilevers for the quantitation of prostate-specific antigen at clinically relevant concentrations. The authors commented that the breakthrough potential afforded by nanocantilevers resides in their extraordinary multiplexing capability. ${ }^{53}$

\section{Dendrimers}

Dendrimers are macromolecular compounds that comprise a series of branches around an inner core, the size and shape of which can be altered as desired, and hence serve as an attractive modality for drug delivery. ${ }^{54-56}$ In a recent publication by Choi et al, ${ }^{57}$ DNA-assembled polyamidoamine dendrimer clusters were prepared for cancer cell-specific targeting. They prepared dendrimer-5-fluorouracil conjugates by acetylation, which release free 5-fluorouracil upon hydrolysis, thus 
minimizing the toxicity of 5-fluorouracil. ${ }^{46,57}$ The unique architecture of dendrimers enables multivalent attachment of imaging probes, as well as targeting moieties; thus, these can also be used as a highly efficient diagnostic tool for cancer imaging. Gadolinium-based magnetic resonance imaging contrast agents can operate at an approximately 100-fold lower concentration than the iodine atoms required for computed tomography imaging. They can be targeted to a single site, which improves the sensitivity of imaging. ${ }^{58,59}$ Phase I clinical trials of Starpharma's dendrimer-based microbicide $\left(\right.$ VivaGel $^{\circledR}$ ) are also the first pharmaceutical clinical investigations of human dendrimers. ${ }^{60}$ Dendrimers are associated with inadequate drug release, a limitation that needs to be addressed, and there is inadequate clinical experience with dendrimers which does not allow designation of these agents as harmless or toxic.

\section{Carbon nanotubes}

Another type of nanodevice for biomarker detection is the carbon nanotube. Carbon nanotubes are carbon cylinders composed of benzene rings that have been used in biology as sensors for detecting DNA and protein as diagnostic devices for the discrimination of different proteins from serum samples and as carriers to deliver drug, vaccine, or protein. ${ }^{61}$ An emerging field in nanotechnology is the exploration of interesting structural, mechanical, electrical, and optical properties of single-walled carbon nanotubes for biological applications including biosensors, molecular transporters for drug delivery, and potential new therapies. ${ }^{4}$ The high optical absorbance of single-walled carbon nanotubes in the nearinfrared region causes heating under laser irradiation, which is useful for destroying cancer cells that are selectively internalized with nanotubes. Current trends in biomedical imaging have focused on the near infrared fluorescence properties of single-walled carbon nanotubes and on surface functionalization. Near infrared fluorescence lies in the biologically transparent region (700-1300 nm) where autofluorescence, absorption, and scattering by blood and tissue are minimized. Surface-functionalized multiwalled carbon nanotubes have also been used successfully for bioimaging purposes. ${ }^{62-64}$ In an in vitro study, drugs bound to carbon nanotubes were shown to be more effectively internalized into cells than free drug alone. ${ }^{65}$ A study subsequently demonstrated that nitrogen-doped, multiwalled carbon nanotubes result in photoablative destruction of kidney cancer cells when excited by near infrared irradiation. This study also demonstrated that effective heat transduction and cellular cytotoxicity depends on nanotube length. Cell death was attributed directly to the photothermal effect generated within the culture, since neither the infrared irradiation itself nor the multiwalled carbon nanotubes were toxic to the cells.

Recent studies with carbon-derived nanomaterials demonstrate platelet aggregation induced by both single-walled and multiwalled carbon nanotubes. ${ }^{66}$ In addition, studies in rodents demonstrated chronic lung inflammation, including foreign body granuloma formation and interstitial fibrosis when high doses of nanotubes were used. ${ }^{67-69}$ In addition, these nanotubes have a tendency to lead to asphyxiation through nanotube clumping in the airways when nonphysiological routes and unrealistic dosages are used. ${ }^{67-69}$

\section{Fullerenes}

A fullerene is any molecule composed entirely of carbon, in the form of a hollow sphere, ellipsoid, or tube. Spherical fullerenes are also called buckyballs, and cylindrical ones are called carbon nanotubes or buckytubes. Fullerenes are similar in structure to graphite, and are composed of stacked graphene sheets of linked hexagonal rings, but they may also contain pentagonal (or sometimes heptagonal) rings. The discovery of fullerenes greatly expanded the number of known carbon allotropes, which until recently were limited to graphite, diamond, and amorphous carbon, such as soot and charcoal. Buckyballs and buckytubes have been the subject of intense research, both for their unique chemistry and for their technological applications, especially in materials science, electronics, and nanotechnology. A recent study demonstrated the inhibition of tumor growth by endohedral metallofullerenol nanoparticles optimized as reactive oxygen species scavengers. ${ }^{70}$ Intraperitoneal injection of $\left[\mathrm{Gd} @ \mathrm{C}_{82}(\mathrm{OH})_{22}\right]_{\mathrm{n}}$ nanoparticles was observed to decrease the activities of enzymes associated with metabolism of reactive oxygen species in tumor-bearing mice, and $\left[\mathrm{Gd} @ \mathrm{C}_{82}(\mathrm{OH})_{22}\right]_{\mathrm{n}}$ nanoparticles also protected cells subjected in vitro to oxidative stress. Studies using human lung adenocarcinoma cells or rat brain capillary endothelial cells demonstrated that $\left[\mathrm{Gd} @ \mathrm{C}_{82}(\mathrm{OH})_{22}\right]_{\mathrm{n}}$ nanoparticles reduced $\mathrm{H}_{2} \mathrm{O}_{2}$-induced reactive oxygen species formation and mitochondrial damage. $\left[\mathrm{Gd} @ \mathrm{C}_{82}(\mathrm{OH})_{22}\right]_{\mathrm{n}}$ nanoparticles efficiently inhibited the growth of malignant tumors in vivo. ${ }^{70}$ Another study compared the photodynamic activity of six functionalized fullerenes with one, two, or three hydrophilic groups or one, two, or three cationic groups. The authors studied three mouse cancer cell lines incubated for 24 hours with fullerenes and illuminated with white light. The order of effectiveness as a photosensitizer was inversely proportional to the degree of substitution of the fullerene nucleus. The monopyrrolidinium fullerene was the most active photosensitizer against all cell 
lines and induced apoptosis 4-6 hours after illumination. The study concluded that certain functionalized fullerenes have potential as novel photodynamic therapy agents and phototoxicity may be mediated both by superoxide and by singlet oxygen.

\section{Other nanoparticles}

Nanoparticles are infinitesimal units with at least one of their dimensions being $\leq 100 \mathrm{~nm}\left(1 \mathrm{~nm}\right.$ being $\left.10^{-9} \mathrm{~m}\right)$. These are currently under intense scientific investigation due to the fact that they are effectively a bridge between bulk materials and atomic or molecular structures, and thus have a wide variety of potential applications in the biomedical, optical, and electronic fields. ${ }^{11,12,71}$ Utilization of nanotechnology for the development of efficient drug delivery systems is one of the most recent developments in medical science. The structure and tunable surfaces of nanoparticles allow them to encapsulate/conjugate single or multiple entities, adapting them as ideal transporters for various anticancer drugs. The surfaces could also be bare or conjugated to targeting ligands like PEG, or aptamer to prevent macrophage uptake of nanoparticles. ${ }^{72}$ Nanoparticles are also developed as imaging contrast agents which makes possible the production of multifunctional nanoparticles with a capacity for targeted tumor imaging and delivery of therapeutic agents. ${ }^{71,73}$ With little modification to provide specific biochemical interactions with the receptors expressed on target cells, nanoparticles could also deliver drugs to the target site, crossing several biological barriers. ${ }^{11,12,71}$

Nanoparticles made up of biodegradable and biocompatible polymers, eg, polylactic acid, poly (DL-lactide-coglycolide acid) (PLGA), starch, and chitosan, have been extensively employed for the delivery of various drugs. ${ }^{72,74}$ In particular, homopolymers and copolymers of lactic acid and polylactic glycolic acid have been extensively used for numerous drug delivery applications. ${ }^{1,72,75}$ Important advantages of these ecofriendly polymers are their history of safe use, proven biocompatibility, and ability to control the time and rate of polymer degradation. The presence of a hydrophilic polymer like PEG increases the circulation time of the nanoparticles by sterically stabilizing them against opsonization. ${ }^{72}$ This property of PEG thus improves the pharmacokinetic and pharmacodynamic properties of the drugs that have been encapsulated in nanoparticles. PEGylation (ie, the attachment of PEG to proteins and drugs) is an upcoming methodology for drug development and has potential to revolutionize medicine by drastically improving the pharmacokinetic and pharmacodynamic properties of administered drugs. ${ }^{76}$ PEGylated polylactic acid/PLGA nanoparticles have been demonstrated to exhibit significantly increased blood circulation time and relatively lowered accumulation in different organs compared with their non-PEGylated counterparts. ${ }^{77-79}$ In vivo experiments also show significantly high accumulation of the PEGylated nanoformulation in tumor tissues due to the enhanced permeation and retention effect. This enhanced permeability and retention is mainly due to the difference in vasculature between tumor tissue and normal tissue.

\section{Nanotechnology and chemoprevention by natural products}

We have introduced for the first time the novel concept of the use of nanotechnology to improve the outcome of chemopreventive intervention and coined the term "nanochemoprevention." ${ }^{\text {" Th }}$ This concept assumes much significance due to the fact that despite outstanding advancement in fundamental cancer biology and chemoprevention by bioactive food components in preclinical settings it has not translated into even limited progress from "bench to bedside" for human use. A few of the reasons that are considered to be responsible for the lack of chemoprevention in the clinical trials are the diverse genetic background of individuals at risk, varied food habits amongst participants, and, most importantly, inefficient systemic delivery and poor bioavailability of active agents. Thus, in order to achieve the maximum response of bioactive food components as chemopreventive agents for human use, strategies that can bypass these limitations are required. Strategies leading to sustained release of the active agents could critically improve their bioavailability and in turn reduce the perceived toxicity associated with the high doses typically required for optimum response to an agent. After our proof-of-principle study, several laboratories worldwide have taken up the concept of nanochemoprevention and, at present, many natural agents are being utilized for chemoprevention in nanotechnology settings. In this paper, we review the data available so far for some of the extensively studied nutraceuticals.

\section{Epigallocatechin-3-gallate}

The notion that nanotechnology could be employed to increase the systemic delivery and bioavailability of any nutraceutical was introduced by our laboratory through a proof-of-principle study. ${ }^{80}$ We employed nanoparticle-mediated delivery for sustained release of a potentially useful chemopreventive agent, epigallocatechin-3-gallate (EGCG), a polyphenol from 
green tea. We encapsulated EGCG in polylactic acid-PEG nanoparticles and assessed its efficacy against human prostate cancer under in vitro and in vivo conditions. In this study, we demonstrated that encapsulated EGCG retains its biological effectiveness with an over 10-fold dose advantage in exerting its efficacy. Shortly after this work, Shutava et al ${ }^{81}$ reported a new type of protein/polyphenol microcapsule formulation of EGCG and type A gelatin using the layer-by-layer assembly method. EGCG in the layer-by-layer assembly was shown to retain its antioxidant activity, and the kinetics of the reaction of 2,2'-azinobis(3-ethylbenzothiazoline-6sulfonic acid) diammonium salt cation radicals with films consisting of 1-10 gelatin/EGCG bilayers was observed to be affected by film structure. The EGCG content in the protein/polyphenol film material was as high as $30 \% \mathrm{w} / \mathrm{w} .{ }^{82}$ A study with the purpose of designing and characterizing two flavonoid-loaded lipid nanocapsules (LNC) by applying the phase inversion process, and to enhance their apparent solubility and/or the stability was later performed. ${ }^{83}$ In that study, it was observed that quercetin-loaded LNC30 (3\%) and LNC60 (2\%) had a particle size of 30.3 and $55.1 \mathrm{~nm}$, respectively, and had significant higher entrapment efficiency. In addition, colloidal suspensions proved to be stable in terms of encapsulation for at least 10 weeks, and quercetin was not oxidized. With simple chemical modification of (-)-EGCG, it was possible to reach very high encapsulation rates $(95 \%)$. The authors obtained stable colloidal suspensions of (-)-EGCG in water over 4 weeks, while free (-)-EGCG solubilized in water exhibited $100 \%$ degradation within 4 hours. In another study, the preparation, activity, and in vitro targeting ability of EGCG:bovine serum albumin (BSA) nanoparticles was evaluated in PC-3 cells. The folate-mediated EGCG:BSA nanoparticle morphology and particle size distribution were uniform, with a mean particle size of $200 \mathrm{~nm}$. Folate-mediated EGCG:BSA nanoparticle uptake by cultured PC-3 cells was 23.65 times the amount of folate-mediated EGCG:BSA in a concentrationdependent manner. The lethality of PC-3 cells treated with folate-mediated EGCG:BSA was $82.8 \%$, while cells treated with EGCG and EGCG-BSA nanoparticles were 58.6\% and $55.1 \%$, respectively. Lethality of PC-3 cells was positively correlated with the amount of nanoparticle uptake. ${ }^{84}$

In another study, polyphenols like EGCG, tannic acid, curcumin, and theaflavin were encased into gelatin-based nanoparticles consisting of a soft gel-like interior with or without a surrounding layer-by-layer shell of polyelectrolytes assembled using the layer-by-layer technique. Nanoparticle-encapsulated EGCG retained its biological activity and blocked hepatocyte growth factor-induced intracellular signaling in the MBA-MD-231 breast cancer cell line as potently as free EGCG. ${ }^{81}$ In a recent study, it was suggested that encapsulation of various catechins of green tea in chitosan nanoparticles enhances their intestinal absorption as a promising strategy for improving their bioavailability. ${ }^{85}$ Poly(lactide-co-epsilon-caprolactone) was successfully developed as an EGCG-eluting polymeric stent which could be utilized for preventing thrombosis, inflammation, and instent restenosis. ${ }^{86}$ In another study, Italia et al also suggested the potential of biodegradable nanoparticles in improving the therapeutic efficacy of EGCG. ${ }^{87}$ In a recently concluded study, EGCG was incorporated into a carbohydrate matrix of gum arabic and maltodextrin, with an encapsulation efficiency of approximately $85 \%{ }^{88}$ This study observed that encapsulated EGCG retained its biological activity, reducing the cell viability and inducing apoptosis of Du145 prostate cancer cells. Clonogenic assay demonstrated that encapsulation of EGCG enhanced its inhibitory effect on cell proliferation $(10 \%-20 \%)$ at lower concentrations (1-2 $\mu \mathrm{M})$ as compared with free EGCG. In another study, the anticancer potential of a polymer-based nanoparticle of EGCG and TF alone and in combination with the anticancer drug, cisplatin, was studied in human cancer lines A549 (lung carcinoma), HeLa (cervical carcinoma), and THP-1 (acute monocytic leukemia) using cell proliferation assay and cell cycle analysis. Encapsulated polyphenols retained their biological effectiveness, with at least a 20 -fold dose advantage over EGCG/TF in exerting anticancer effects and also enhanced the potential of cisplatin. Subsequently, encapsulated polyphenols alone or in combination with cisplatin were more effective in inhibiting cell proliferation, metastasis, angiogenesis, and apoptosis biomarkers. ${ }^{89}$ Another group recently studied the efficacy of EGCG nanoparticles in a mouse model of bladder cancer. ${ }^{90}$ EGCG was physically attached onto the surface of nanogold particles. The anticancer activity of the EGCG-adsorbed nanogold particles was investigated in $\mathrm{C} 3 \mathrm{H} / \mathrm{HeN}$ mice subcutaneously implanted with MBT-2 murine bladder tumor cells. EGCG nanogold particles were confirmed to inhibit tumor cell growth by apoptosis. Additionally, the tumors were observed to be suppressed by injecting EGCG nanogold particles directly into the tumor site. In this study, the prepared EGCG nanogold particles were confirmed to be more effective than free EGCG in inhibiting bladder tumors in a mouse model.

Because oral consumption is the most desired and acceptable form of delivery of chemopreventive agents, it is of extreme importance to resolve the problem of oral 
consumption of nanoencapsulated EGCG and other bioactive food components by incorporating biodegradable polymers suitable for oral delivery as the starting material which will be more stable in the acidic environment of the gut and release the agent slowly for absorption by the body. Our recent unpublished work suggests that nanoformulated EGCG has great potential, and we have observed a sustained-release phenomenon for EGCG by making our nanoparticle preparation optimal for oral delivery.

\section{Resveratrol}

Resveratrol (3,5,4'-trihydroxystilbene), a phytoalexin antioxidant found in grapes, red wines, berries, and peanuts, has been shown to afford protection against several diseases, including cancer. ${ }^{91-93}$ However, most of these results have failed to be replicated in humans, mainly due to a very short half-life. This agent is rapidly glucuronated and sulfonated, and is a lipophilic agent, so failed miserably when tested in clinical settings. Nanotechnology-based approaches are currently being utilized to enhance the bioavailability of resveratrol, and significant progress have been made in this area of research.

The first nanoformulation of resveratrol was made with chitosan nanoparticles, and a study suggested that these nanoformulations have sustained release in vitro. In this study, the rate of release was slowed down with an increase in solidification agents. ${ }^{94}$ In another study, resveratrol-loaded nanoparticles at lower concentrations were observed to lead to significantly more cell death as compared with an equivalent dose of free resveratrol, and this difference in cytotoxicity was found not to be abrogated by inclusion of vitamin E. ${ }^{95}$ A further study suggested that 12 hours of preincubation with resveratrol-loaded nanoparticles protects cells from beta-amyloid peptide $\left(\right.$ Abeta $\left.^{\circledR}\right)$-induced damage in a dose-dependent manner by attenuating intracellular oxidative stress and caspase- 3 activity. ${ }^{96}$

In a recent study, Narayanan et $\mathrm{al}^{97}$ used liposomeencapsulated curcumin and resveratrol individually and in combination in male $\mathrm{B} 6 \mathrm{C} 3 \mathrm{~F} 1 / \mathrm{J}$ and prostate-specific PTEN knockout mice. In vitro assays using PTEN-CaP8 cancer cells were also performed to investigate the combined effects of curcumin and resveratrol. In this study, analysis of serum and prostate tissues by high-pressure liquid chromatography showed a significant increase in the curcumin level when liposome-encapsulated curcumin was coadministered with liposomal resveratrol. Combination of liposomal formulations of curcumin and resveratrol significantly decreased prostatic adenocarcinoma in vivo in PTEN mice, and in vitro studies revealed that curcumin plus resveratrol effectively inhibited cell growth and induced apoptosis. Findings from this study for the first time provide evidence on phytochemicals in combination to enhance chemopreventive efficacy in prostate cancer. In another study, nanosuspensions of resveratrol $(5 \%)$ were produced for dermal application. In this study, four nanosuspensions were investigated using the stabilizers Tween 80, Poloxamer 188, Plantacare 2000, and Inutec SP1. Nanocrystal sizes were about $150 \mathrm{~nm}$ (Poloxamer, Plantacare) and about $200 \mathrm{~nm}$ (Tween, Inutec), and no amorphous fraction was detected in the nanocrystals. In a short-term stability study (30 days, room temperature), the nanosuspensions with $2 \%$ stabilizer proved to be either less stable or to have no stability advantage over the $1 \%$ formulations. In this study, formulations with $1 \%$ stabilizer were stable in the short-term study, and Plantacare and Inutec demonstrated the best stabilization. ${ }^{98}$ Next, solid lipid nanoparticles were used as a carrier for resveratrol. ${ }^{99}$ The effects of solid lipid nanoparticles, empty or loaded with resveratrol (SLN-RSV), on the internalization, growth, morphology, metabolic activity, and genetic material of keratinocytes were compared with those of resveratrol in solution. Fluorescence images clearly showed that solid lipid nanoparticles with a size below $180 \mathrm{~nm}$ move promptly across the cell membrane, distribute throughout the cytosol, move successively among different cellular levels, and localize in the perinuclear region without inducing any cytotoxicity. The solubility, stability, and intracellular delivery of resveratrol were all increased by loading into solid lipid nanoparticles. The release profile of resveratrol showed a biphasic pattern, reflecting its distribution in solid lipid nanoparticles. Resveratrol in solution was slightly cytotoxic, and this was prevented by loading resveratrol into solid lipid nanoparticles, which preserved the cell morphology. The cytostatic effect of SLN-RSV was more evident than that of resveratrol in solution. Delivery of resveratrol by solid lipid nanoparticles contributes to the effectiveness of resveratrol in decreasing cell proliferation, with potential benefits for prevention of skin cancer. ${ }^{99}$

Although not much progress has been made as yet on the nanotechnology-based anticancer potential of resveratrol, it should be noted that this field is still very primitive, and thus more research is required to be able to realize the beneficial activity of this agent.

\section{Curcumin}

Another bioactive food agent that has been extensively and widely studied in the nanotechnology setting is curcumin, the principal curcuminoid of the popular Indian spice 
turmeric (Curcuma longa), a plant typically grown and used in Southeast Asia. ${ }^{100}$ This agent has also suffered from poor availability in biological settings, and thus has not being able to be translated to the clinic, despite tremendous efficacy in the preclinical setting. The low bioavailability of curcumin is attributed to poor oral absorption and rapid metabolism in the intestines and liver. Nanocarriers have the capacity to increase the solubility of this agent and decrease the rate of biotransformation. The first attempt to incorporate nanotechnology for curcumin was by Tonnesen, ${ }^{101}$ who observed that micellar solubilization could stabilize curcumin against hydrolytic reaction with a half-life of 2 months. The idea of a nanoformulation of curcumin was later revisited by another study in which curcuminoid-loaded solid lipid nanoparticles were developed. ${ }^{102}$ Although these two studies did not identify any anticancer potential of curcumin, they did establish the concept of nanoformulation of this agent. The first study that investigated the efficacy of curcumin in the nanotechnology setting for its cancer chemopreventive effects came from Bisht et al. ${ }^{103}$ This study utilized the micellar aggregates of cross-linked and random copolymers of N-isopropylacrylamide, with N-vinyl-2-pyrrolidone and PEG monoacrylate to encapsulate curcumin. The data from this study demonstrated comparable in vitro therapeutic efficacy for nanoformulated curcumin and free curcumin against a panel of human pancreatic cancer cell lines, as assessed by cell viability and clonogenicity assays. Further, the mechanism of action of nanoformulated curcumin was observed to mirror that of free curcumin, including induction of cellular apoptosis, blockade of nuclear factor kappa B activation, and downregulation of steady-state levels of multiple proinflammatory cytokines (interleukin-6, interleukin-8, and tumor necrosis factor alpha). Most of the results from this study demonstrated that both formulations of curcumin were equally potent, with the nanoformulated curcumin demonstrating better results at lower doses. ${ }^{103}$ In another study, Sahu et al ${ }^{104}$ synthesized a novel polymeric amphiphile with methoxy poly(ethylene glycol) (mPEG) as the hydrophilic segment and palmitic acid as the hydrophobic segment. The conjugate, prepared in a single-step reaction, showed minimal toxicity in HeLa cells. This study suggested a mechanism to make a hydrophobic drug like curcumin readily soluble in an aqueous system, but failed to demonstrate any advantage of nanoformulation.

Thangapazham et $\mathrm{al}^{105}$ in another study demonstrated better efficacy for nanoformulated curcumin compared with free curcumin. Their study enhanced targeted delivery of curcumin in prostate cancer treatment by incorporating this agent into liposomes coated with prostate membrane-specific antigen-specific antibodies. The antiproliferative activity of liposomal curcumin was studied using two human prostate cancer cell lines (LNCaP and C4-2B), and treatment of cells with liposomal curcumin resulted in at least $70 \%-80 \%$ inhibition of cellular proliferation without affecting their viability, with a 10-fold dose advantage over free curcumin. ${ }^{105}$ In another study, curcumin was nanoformulated with three biocompatible polymers, ie, alginate, chitosan, and Pluronic ${ }^{\circledR}$ by ionotropic pregelation followed by polycationic crosslinking. Pluronic F127 was used to enhance the solubility of curcumin in the alginate-chitosan nanoparticles. This study demonstrated cellular internalization of curcumin-loaded composite nanoparticles. ${ }^{106}$ A further study also demonstrated that a curcumin-loaded poly(caprolactone) nanofiber matrix is bioactive and has potential as a wound dressing, with reduced induction of inflammation and an increased rate of wound closure. ${ }^{107}$ In a different study, a PEGylated curcumin conjugate was demonstrated to have much more potent effects on pancreatic cancer cell growth inhibition than free curcumin. ${ }^{108}$

Another study demonstrated the promise of nanoparticles for oral delivery of curcumin by preparing nanoformulated curcumin using an emulsion technique. This study suggested that the in vitro release of curcumin was predominantly by a diffusion phenomenon and followed Higuchi's release pattern. In vivo pharmacokinetics revealed that curcumin entrapped in nanoparticles demonstrated at least a nine-fold increase in oral bioavailability when compared with curcumin administered with piperine as an absorption enhancer. ${ }^{109}$ A recent study reported composite nanoparticles prepared using three biocompatible polymers, alginate, chitosan, and Pluronic by ionotropic pregelation followed by polycationic cross-linking nanoformulation of curcumin with a tripolymeric composite for delivery to cancer cells. The encapsulation efficiency of curcumin in the composite nanoparticles showed a considerable increase compared with the alginate-chitosan nanoparticles without Pluronic. These composite nanoparticles were observed to have a suitable size distribution, drug encapsulation efficiency, and drug-release kinetics. The half-maximal inhibitory concentrations for free curcumin and encapsulated curcumin were found to be $13.28 \mu \mathrm{M}$ and $14.34 \mu \mathrm{M}$, respectively. ${ }^{110}$

Another important study in the area of nanoformulated curcumin came from Anand et al, who encapsulated curcumin in PLGA and a stabilizer (PEG) with over 97.5\% efficiency. ${ }^{111}$ In this study, the authors observed that the nanoformulated 
curcumin exhibited very rapid and more efficient cellular uptake than free curcumin in vitro. Nanoformulated curcumin was also seen to be at least as potent as or more potent than curcumin in inducing apoptosis of leukemic cells and in suppressing proliferation of various tumor cell lines. When examined by electrophoretic gel shift mobility assay, curcumin nanoparticles were more active than curcumin in inhibiting tumor necrosis factor-induced NF-kappaB activation and in suppression of NF-kappaB-regulated proteins involved in cell proliferation (cyclin D1), invasion (matrix metallopeptidase-9), and angiogenesis (vascular endothelial growth factor). In mice, curcumin nanoparticles were more bioavailable and had a longer half-life than curcumin. In another study, Mukherjee and Vishwanathan ${ }^{112}$ demonstrated successful formation of smooth and spherical curcumin-loaded PLGA nanospheres with an encapsulation efficiency of around $91 \%$. This study demonstrated robust intracellular uptake of nanospheres in prostate cancer cells, and cell viability studies revealed that the curcumin-loaded nanospheres were able to exert a more pronounced effect on the cancer cells as compared with free curcumin. ${ }^{112}$ More recently, an efficacious formulation of curcumin, including a nanocrystal solid dispersion, amorphous solid dispersion, and nanoemulsion, were designed with the aim of improving physicochemical and pharmacokinetic properties. All curcumin formulations exhibited marked improvement in the dissolution behavior when compared with crystalline curcumin. Significant improvement in pharmacokinetic behavior was observed in the newly developed formulations, as evidenced by a 12-fold, 16-fold, and nine-fold increase in oral bioavailability for the amorphous solid dispersion, nanocrystal solid dispersion, and nanoemulsion, respectively. ${ }^{113}$ Sou et al ${ }^{114}$ investigated self-organized mixed assemblies of curcumin and a poly(oxyethylene) cholesteryl ether (PEGChol). In this study, curcumin was assembled with PEG-Chol to form nanosized assemblies (around $10 \mathrm{~nm}$ ) of micelles. In contrast with the rapid decomposition of free curcumin due to hydrolysis, curcumin was highly stabilized in the nanoparticles, especially at curcumin concentrations below $40 \mathrm{~mol} \%$. A cell viability assay revealed that the cytotoxic activity of the curcumin/PEG-Chol nanoparticles against myeloma cells was higher than those of free curcumin at $1 \mu \mathrm{M}$. On the other hand, both the curcumin/PEG-Chol nanoparticles and PEG-Chol micelles had significant cytotoxicity to myeloma cells at $5 \mu \mathrm{M} .{ }^{114}$

A study was recently undertaken with the objective of enhancing the bioavailability of curcumin along with reducing the required dose through selective targeting to the colon. ${ }^{115}$ The authors utilized Eudragit ${ }^{\circledR}$ S100 to aid in targeting because the polymer dissolves at colonic $\mathrm{pH}$ to result in selective local release of the entrapped drug. The authors synthesized nanometric, homogeneous, spherical particles with an encapsulation efficiency of around $72 \%$. Inhibition of cell growth in an HT-29 cell line was almost doubled by nanoparticles as compared with curcumin alone at all the tested concentrations. ${ }^{115}$ More recently, two studies by Yallapu et $\mathrm{al}^{116,117}$ tested the efficacy of nanoformulated curcumin in cancer therapeutics. In the first study, ${ }^{116}$ the authors encapsulated curcumin into PLGA nanoparticles in the presence of polyvinyl alcohol and poly(L-lysine) stabilizers. The authors observed that the optimized curcumin nanoformulation, compared with free curcumin, had two-fold and six-fold increases in uptake by cisplatin-resistant A2780CP ovarian and metastatic MDA-MB-231 breast cancer cells, respectively. In these cells, the curcumin nanoformulation showed improved anticancer potential in cell proliferation and clonogenic assays compared with free curcumin. This effect was correlated with enhanced apoptosis induced by the curcumin nanoformulation. Further, the authors demonstrated the antibody conjugation compatibility of our PLGA-NP formulation. ${ }^{116}$ In their next study, a PLGA nanoformulation of curcumin was successfully generated, and steady and prolonged release of curcumin, antibody conjugation capability, and effective inhibition of ovarian cancer cell growth was successfully tested. ${ }^{117}$ These studies suggest that curcumin could be successfully formulated by utilizing nanotechnology, and the resulting formulation was demonstrated to have better efficacy against a variety of cancer cells. These studies further suggested better bioavailability under in vivo situations, but more studies are required to take the research into clinical practice.

\section{Paclitaxel}

Paclitaxel, a potent anticancer agent, has stimulated intense research effort over recent years. It has been shown to have activity against a number of leukemias and solid tumors in the breast, ovary, brain, and lung in humans. ${ }^{118-121}$ Paclitaxel is among the first clinically successful chemotherapy drugs approved by the US Food and Drug Administration to have originated from natural sources. It was isolated from the bark of the Pacific yew tree in 1971, developed commercially by Bristol-Myers Squibb, and is marketed as Taxol ${ }^{\circledR}$. This agent suffers from being water-insoluble, and ethanol or Cremophor EL are generally used for the purpose of delivery. Cremophor EL is associated with a severe allergic reaction, with symptoms including tightness in the chest, shortness of 
breath, and reactions consistent with severe anaphylaxis. In the first study of its kind, a polymeric drug delivery system was developed for paclitaxel, which was intended to be administered intravenously, capable of improving the therapeutic index of the drug, and devoid of the adverse effects of Cremophor EL. ${ }^{122}$ Paclitaxel-loaded PLGA nanoparticles were prepared by the interfacial deposition method. In this study, the release behavior of paclitaxel from the developed nanoparticles exhibited a biphasic pattern characterized by an initial fast release during the first 24 hours, followed by slower continuous release. The in vitro results demonstrated that incorporation of paclitaxel in nanoparticles strongly enhanced the cytotoxic effect of the drug, with the effect being more relevant at prolonged incubation times. ${ }^{122}$ Feng et al in another study formulated paclitaxel in PLGA nanoparticles by a modified solvent extraction/evaporation technique. ${ }^{123}$ In this study, it was found that these natural emulsifiers had great advantages for nanoparticulate formulation of paclitaxel over the traditional macromolecular emulsifiers, such as polyvinyl alcohol. Nanoparticles of the desired small size and narrow size distribution were obtained. The study also suggested that the formulation could be modified to achieve drug encapsulation efficiency as high as $100 \%$ and that the release kinetics could be controlled. An HT-29 cancer cell line experiment showed that, after 24 hours of incubation, cell mortality caused by the drug administered as a nanoparticle formulation could be more than 13 times higher than that caused by the free drug under similar conditions. ${ }^{123}$ Another study $^{124}$ determined the efficacy of paclitaxel loaded into sterically stabilized, biocompatible, and biodegradable sterically stabilized mixed phospholipid nanomicelles (SSMM) and actively targeted vasoactive intestinal peptide-grafted SSMM (SSMM-VIP) in circumventing P glycoprotein-mediated paclitaxel resistance in BC19/3 cells, a human breast cancer cell line that expresses $>10$-fold higher $\mathrm{P}$ glycoprotein than its parental sensitive cell line, MCF-7. The study found that in drug-sensitive MCF-7 cells, paclitaxel loaded into SSMM (P-SSMM) and SSMM-VIP (P-SSMM-VIP) significantly inhibited cell growth in a dose-dependent fashion $(P<0.05)$. Both formulations were approximately sevenfold more potent than paclitaxel dissolved in dimethylsulfoxide (P-DMSO), with P-SSMM and P-SSMM-VIP showing similar efficacy. By contrast, in drug-resistant BC19/3 cells, P-SSMM-VIP was significantly more effective than either P-SSMM or P-DMSO (approximately two-fold and fivefold, respectively; $P<0.05) .{ }^{124}$ A study was performed to determine the efficacy of paclitaxel-loaded biodegradable nanoparticles on tumor inhibition. ${ }^{125}$ The antiproliferative activity of the nanoparticles was determined in a human prostate cancer cell line (PC3) and their effect on tumor inhibition in a murine model of prostate cancer. Nanoparticles under in vitro conditions exhibited sustained release of the encapsulated drug ( $60 \%$ release in 60 days). The $\mathrm{IC}_{50}$ of the drug with paclitaxel-conjugated theaflavin nanoparticles was about five-fold lower than that with unconjugated paclitaxel nanoparticles or the drug in solution. Animals that received a single-dose intratumoral injection of paclitaxelconjugated theaflavin nanoparticles (paclitaxel $4 \mathrm{mg} / \mathrm{kg}$ ) demonstrated complete tumor regression and a greater survival rate than those that received either paclitaxel nanoparticles or a paclitaxel-Cremophor EL formulation. In conclusion, this study demonstrated sustained drug release from the nanoparticles and greater antitumor activity following conjugation to the theaflavin ligand. ${ }^{125} \mathrm{~A}$ recent study developed a novel, highly water-soluble poly(L- $\gamma$ glutamyl-glutamine)-paclitaxel nanoconjugate (PGG-PTX). The potency of PGG-PTX when tested in vitro against the human lung cancer H460 cell line was comparable with that of other known polymer-paclitaxel conjugates. However, PGG-PTX demonstrates lower toxicity compared with PGAPTX in mice. The maximum tolerated dose of PGG-PTX was found to be $350 \mathrm{mg}$ paclitaxel per $\mathrm{kg}$, which is 2.2-fold higher than the maximum tolerated dose of $160 \mathrm{mg}$ paclitaxel per $\mathrm{kg}$ reported for PGA-PTX. ${ }^{126}$ In a very recent study, cationic micellar nanoparticles self-assembled from a biodegradable amphiphilic copolymer were used to deliver human TRAIL and paclitaxel simultaneously. ${ }^{127}$ Polyplexes formed between paclitaxel-loaded nanoparticles and TRAIL was observed to be stable, with a size of approximately $180 \mathrm{~nm}$ and a zeta potential at about $75 \mathrm{mV}$. Anticancer effects and apoptotic pathway mechanisms of this drug-and-protein codelivery system were investigated in various human breast cancer cell lines with different TRAIL sensitivity. The codelivery nanoparticulate system induced synergistic anticancer activity with limited toxicity in noncancerous cells. ${ }^{127}$

\section{Conclusion and future prospects}

For several years, nanotechnology has been utilized for diagnosis and treatment of cancers. . $^{3,5,8,59,61,63,87,128-132}$ Our proof-of-principle study ${ }^{80}$ demonstrated the usefulness of nanoparticulate technology to enhance the therapeutic effectiveness of natural agents, using EGCG in our case. Based on our study, the concept was very well utilized by researchers worldwide and, as described above, the outcome of the studies is very convincing. Nanotechnology-mediated delivery of bioactive food components is very effective because of 
Table I Some examples of nanocarrier-based drugs on the market

\begin{tabular}{|c|c|c|}
\hline Commercial name & Type of nanoparticle/drug & Area of activity \\
\hline Abraxane $^{\circledR}$ & Nanoparticulate albumin/paclitaxel & Several cancers \\
\hline Aurimune ${ }^{\circledR}$ & Colloidal gold/TNF & Solid tumors \\
\hline Combidex $^{\circledR}$ & Iron oxide nanoparticles & Tumor imaging \\
\hline Cyclosert $^{\circledR}$ & Cyclodextrin nanoparticles & Solid tumors \\
\hline Doxil $^{\circledR}$ & PEGylated liposomes/doxorubicin & Ovarian cancer \\
\hline$|N G N-40|^{\circledR}$ & Liposomal/FUSI & Lung cancer \\
\hline Megace $\mathrm{ES}^{\circledR}$ & Nanocrystal/megestrol acetate & Breast cancer \\
\hline SGT-53 ${ }^{\circledR}$ & Liposome TF antibody/p53 gene & Solid tumors \\
\hline Zinostatin/stimalmar ${ }^{\circledast}$ & Polymer-protein conjugate/SMANCS & Hepatocellular carcinoma \\
\hline Oncaspar $^{\circledR}$ & Polymer-protein conjugate/PEG-L-asparaginase & Acute lymphoblastic leukemia \\
\hline DaunoXome ${ }^{\circledR}$ & Liposomes/daunorubicin & Kaposi's sarcoma \\
\hline Myocet $^{\circledR}$ & Liposomes/doxorubicin & $\begin{array}{l}\text { Combinational therapy of breast cancer, } \\
\text { ovarian cancer and Kaposi's sarcoma }\end{array}$ \\
\hline Onco TCS ${ }^{\circledR}$ & Liposomes/vincristine & Relapsed aggressive non-Hodgkin's lymphoma \\
\hline Bexxar $^{\circledast}$ & $\begin{array}{l}\text { Radioimmunoconjugate/anti-CD20 conjugated } \\
\text { to iodine- }|3|\end{array}$ & $\begin{array}{l}\text { Relapsed or refractory, low-grade, follicular } \\
\text { or transformed non-Hodgkin's lymphoma }\end{array}$ \\
\hline
\end{tabular}

Abbreviations: PEG, polyethylene glycol; SMANCS, styrene maleic acid neocarzinostatin; TNF, tumor necrosis factor.

the fact that nanoparticles rarely pose any toxicity to normal cells. ${ }^{133}$ However, further verification of the studies is urgently needed in appropriate animal systems and in clinical research. Moreover, being biodegradable, these nanoparticles are considered to be safe. ${ }^{72}$ Our research and other studies on the subject suggest that nanotechnology could be utilized with considerable advantages over currently employed chemopreventive and chemotherapeutic approaches for cancer. Apart from the nanochemoprevention side of nanotechnology, studies worldwide have shown that nanotechnology is a plausible approach for diagnosis, imaging, and therapeutics. Considerable investigation is now being devoted to nanoparticle-based delivery of various drugs. A number of nanotechnology-based constructs are currently in clinical or preclinical development, and several of these are already approved by the Food and Drug Administration. Some of the nanotechnology-based drugs that are currently available in the market are listed in Table 1 . We suggest that the concept of nanomedicine for cancer should be explored further for its potential use in detection, prevention, and therapy of cancer. Nanotechnology could be developed as an inexpensive, tolerable, and readily applicable approach for cancer control and management. In addition, the advancement in nanochemoprevention might help us to achieve higher concentrations of phytochemicals which are unattainable when the agents are provided as part of a regular diet. It is assumed that a cure for cancer will be available by the year $2015^{75,134}$ and it is also anticipated that nanotechnology will be a $\$ 1$ trillion industry by that time, with most of the impact focusing on health care and cancer therapy. There is some cautiousness that prospective research needs to address the potential long-term toxicity, degradation, and metabolism of nanotechnology agents being utilized for integrated imaging, detection, and therapy. If everything falls into place at the right time with nanotechnology and its existing and forthcoming applications for cancer we could expect success in the very near future.

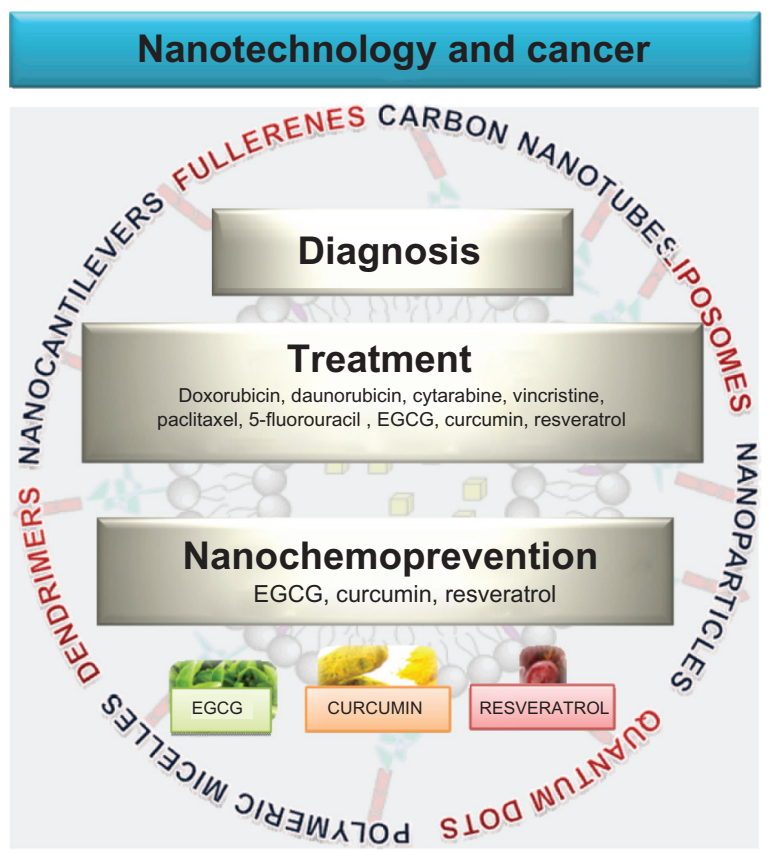

Figure I Nanotechnology in cancer treatment, diagnosis and prevention. Nanotechnology is being developed in cancer primarily for treatment and diagnosis. Liposomes and nanoparticles are now extensively utilized for delivery of chemotherapeutic agents directly to the target sites. Other drug delivery carriers developed include quantum dots, polymeric micelles, dendrimers and carbon nanotubes. Cancer diagnosis and detection has been benefited by the use of quantum dots, nanocantilevers, and carbon nanotubes. More recently, nanotechnology has also been utilized for delivery of natural products such as EGCG, resveratrol and curcumin in the hopes that this technology could also benefit cancer prevention. Abbreviation: EGCG, epigallocatechin-3-gallate. 


\section{Acknowledgment}

This work was supported by a US Public Health Service grant (T32AR055893) and an American Cancer Society grant (MRSG-11-019-01-CNE).

\section{Disclosure}

The authors report no conflicts of interest in this work.

\section{References}

1. Nie S, Xing Y, Kim GJ, Simons JW. Nanotechnology applications in cancer. Annu Rev Biomed Eng. 2007;9:257-288.

2. Niemeyer CM. Semi-synthetic nucleic acid-protein conjugates: applications in life sciences and nanobiotechnology. J Biotechnol. 2001; 82(1):47-66.

3. Nishiyama N. Nanomedicine: nanocarriers shape up for long life. Nat Nanotechnol. 2007;2(4):203-204.

4. Ferrari M. Cancer nanotechnology: opportunities and challenges. Nat Rev Cancer. 2005;5(3):161-171.

5. Cuenca AG, Jiang H, Hochwald SN, Delano M, Cance WG, Grobmyer SR. Emerging implications of nanotechnology on cancer diagnostics and therapeutics. Cancer. 2006;107(3):459-466.

6. Wang X, Yang L, Chen ZG, Shin DM. Application of nanotechnology in cancer therapy and imaging. CA Cancer J Clin. 2008;58(2):97-110.

7. McNeil SE. Nanoparticle therapeutics: a personal perspective. Wiley Interdiscip Rev Nanomed Nanobiotechnol. 2009;1(3):264-271.

8. Freitas RA Jr. What is nanomedicine? Nanomedicine. 2005;1(1):2-9.

9. Freitas RA Jr. Current status of nanomedicine and medical nanorobotics. J Comput Theor Nanos. 2005;2(1):1-25.

10. Torchilin V. Antibody-modified liposomes for cancer chemotherapy. Expert Opin Drug Deliv. 2008;5(9):1003-1025.

11. Vasir JK, Labhasetwar V. Biodegradable nanoparticles for cytosolic delivery of therapeutics. Adv Drug Deliv Rev. 2007;59(8):718-728.

12. Sahoo SK, Labhasetwar V. Nanotech approaches to drug delivery and imaging. Drug Discov Today. 2003;8(24):1112-1120.

13. Barreto JA, O'Malley W, Kubeil M, Graham B, Stephan H, Spiccia L. Nanomaterials: applications in cancer imaging and therapy. Adv Mater. 2011;23(12):H18-H40.

14. Judson I, Radford JA, Harris M, et al. Randomised phase II trial of pegylated liposomal doxorubicin (DOXIL/CAELYX) versus doxorubicin in the treatment of advanced or metastatic soft tissue sarcoma: a study by the EORTC Soft Tissue and Bone Sarcoma Group. Eur J Cancer. 2001;37(7):870-877.

15. Hubert A, Lyass O, Pode D, Gabizon A. Doxil (Caelyx): an exploratory study with pharmacokinetics in patients with hormone-refractory prostate cancer. Anticancer Drugs. 2000;11(2):123-127.

16. Forssen EA, Male-Brune R, Adler-Moore JP, et al. Fluorescence imaging studies for the disposition of daunorubicin liposomes (DaunoXome) within tumor tissue. Cancer Res. 1996;56(9):2066-2075.

17. Guaglianone P, Chan K, DelaFlor-Weiss E, et al. Phase I and pharmacologic study of liposomal daunorubicin (DaunoXome). Invest New Drugs. 1994;12(2):103-110.

18. Jaeckle KA, Batchelor T, O'Day SJ, et al. An open label trial of sustained-release cytarabine (DepoCyt) for the intrathecal treatment of solid tumor neoplastic meningitis. J Neurooncol. 2002;57(3): 231-239.

19. Glantz MJ, Jaeckle KA, Chamberlain MC, et al. A randomized controlled trial comparing intrathecal sustained-release cytarabine (DepoCyt) to intrathecal methotrexate in patients with neoplastic meningitis from solid tumors. Clin Cancer Res. 1999;5(11):3394-3402.

20. Vincristine liposomal - INEX: lipid-encapsulated vincristine, Onco TCS, transmembrane carrier system - vincristine, vincacine, vincristine sulfate liposomes for injection, VSLI. Drugs R D. 2004;5(2): 119-123.
21. Fassas A, Anagnostopoulos A. The use of liposomal daunorubicin (DaunoXome) in acute myeloid leukemia. Leuk Lymphoma. 2005; 46(6):795-802.

22. Charrois GJ, Allen TM. Drug release rate influences the pharmacokinetics, biodistribution, therapeutic activity, and toxicity of pegylated liposomal doxorubicin formulations in murine breast cancer. Biochim Biophys Acta. 2004;1663(1-2):167-177.

23. Simoes S, Moreira JN, Fonseca C, Duzgunes N, de Lima MC. On the formulation of $\mathrm{pH}$-sensitive liposomes with long circulation times. $A d v$ Drug Deliv Rev. 2004;56(7):947-965.

24. Leamon CP, Cooper SR, Hardee GE. Folate-liposome-mediated antisense oligodeoxynucleotide targeting to cancer cells: evaluation in vitro and in vivo. Bioconjug Chem. 2003;14(4):738-747.

25. Orive G, Gascon AR, Hernandez RM, Dominguez-Gil A, Pedraz JL. Techniques: new approaches to the delivery of biopharmaceuticals. Trends Pharmacol Sci. 2004;25(7):382-387.

26. Slingerland M, Guchelaar HJ, Gelderblom H. Liposomal drug formulations in cancer therapy: 15 years along the road. Drug Discov Today. September 29, 2011. [Epub ahead of print.]

27. Chan A, Shih V, Tham Chee K. Liposomal doxorubicin-associated acute hypersensitivity despite appropriate preventive measures. J Oncol Pharm Pract. 2007;13(2):105-107.

28. Szebeni J. Complement activation-related pseudoallergy caused by amphiphilic drug carriers: the role of lipoproteins. Curr Drug Deliv. 2005;2(4):443-449.

29. Veal GJ, Griffin MJ, Price E, et al. A phase I study in paediatric patients to evaluate the safety and pharmacokinetics of SPI-77, a liposome encapsulated formulation of cisplatin. Br J Cancer. 2001;84(8): 1029-1035.

30. White SC, Lorigan P, Margison GP, et al. Phase II study of SPI-77 (sterically stabilised liposomal cisplatin) in advanced non-small-cell lung cancer. Br J Cancer. 2006;95(7):822-828.

31. Steele JP, O'Doherty CA, Shamash J, et al. Phase II trial of liposomal daunorubicin in malignant pleural mesothelioma. Ann Oncol. 2001; 12(4):497-499.

32. Xing Y, Smith AM, Agrawal A, Ruan G, Nie S. Molecular profiling of single cancer cells and clinical tissue specimens with semiconductor quantum dots. Int $J$ Nanomedicine. 2006;1(4):473-481.

33. Seydel C. Quantum dots get wet. Science. 2003;300(5616):80-81.

34. Bruchez M Jr, Moronne M, Gin P, Weiss S, Alivisatos AP. Semiconductor nanocrystals as fluorescent biological labels. Science. 1998;281(5385):2013-2016.

35. Pinaud F, Michalet X, Bentolila LA, et al. Advances in fluorescence imaging with quantum dot bio-probes. Biomaterials. 2006;27(9): 1679-1687.

36. Gao X, Yang L, Petros JA, Marshall FF, Simons JW, Nie S. In vivo molecular and cellular imaging with quantum dots. Curr Opin Biotechnol. 2005;16(1):63-72.

37. Michalet X, Pinaud FF, Bentolila LA, et al. Quantum dots for live cells, in vivo imaging, and diagnostics. Science. 2005;307(5709):538-544.

38. Alivisatos P. The use of nanocrystals in biological detection. Nat Biotechnol. 2004;22(1):47-52.

39. Shiohara A, Hoshino A, Hanaki K, Suzuki K, Yamamoto K. On the cyto-toxicity caused by quantum dots. Microbiol Immunol. 2004;48(9): 669-675.

40. Lovric J, Bazzi HS, Cuie Y, Fortin GR, Winnik FM, Maysinger D. Differences in subcellular distribution and toxicity of green and red emitting CdTe quantum dots. J Mol Med (Berl). 2005;83(5): 377-385.

41. Hoshino A, Manabe N, Fujioka K, Suzuki K, Yasuhara M, Yamamoto K. Use of fluorescent quantum dot bioconjugates for cellular imaging of immune cells, cell organelle labeling, and nanomedicine: surface modification regulates biological function, including cytotoxicity. J Artif Organs. 2007;10(3):149-157.

42. Choi AO, Cho SJ, Desbarats J, Lovric J, Maysinger D. Quantum dot-induced cell death involves Fas upregulation and lipid peroxidation in human neuroblastoma cells. J Nanobiotechnol. 2007;5:1. 
43. Gao X, Chung LW, Nie S. Quantum dots for in vivo molecular and cellular imaging. Methods Mol Biol. 2007;374:135-145.

44. Smith AM, Ruan G, Rhyner MN, Nie S. Engineering luminescent quantum dots for in vivo molecular and cellular imaging. Ann Biomed Eng. 2006;34(1):3-14.

45. Dubertret B, Skourides P, Norris DJ, Noireaux V, Brivanlou AH, Libchaber A. In vivo imaging of quantum dots encapsulated in phospholipid micelles. Science. 2002;298(5599):1759-1762.

46. Rawat M, Singh D, Saraf S. Nanocarriers: promising vehicle for bioactive drugs. Biol Pharm Bull. 2006;29(9):1790-1798.

47. Hamaguchi T, Matsumura Y, Suzuki M, et al. NK105, a paclitaxelincorporating micellar nanoparticle formulation, can extend in vivo antitumour activity and reduce the neurotoxicity of paclitaxel. $\mathrm{Br} J$ Cancer. 2005;92(7):1240-1246.

48. Lavasanifar A, Samuel J, Kwon GS. Poly(ethylene oxide)-block-poly(Lamino acid) micelles for drug delivery. Adv Drug Deliv Rev. 2002;54(2): 169-190.

49. Bae Y, Nishiyama N, Fukushima S, Koyama H, Yasuhiro M, Kataoka K. Preparation and biological characterization of polymeric micelle drug carriers with intracellular $\mathrm{pH}$-triggered drug release property: tumor permeability, controlled subcellular drug distribution, and enhanced in vivo antitumor efficacy. Bioconjug Chem. 2005;16(1):122-130.

50. Nakanishi T, Fukushima S, Okamoto K, et al. Development of the polymer micelle carrier system for doxorubicin. $J$ Control Release. 2001;74(1-3):295-302.

51. Torchilin VP, Lukyanov AN, Gao Z, Papahadjopoulos-Sternberg B. Immunomicelles: targeted pharmaceutical carriers for poorly soluble drugs. Proc Natl Acad Sci U S A. 2003;100(10):6039-6044.

52. Mohanty C, Acharya S, Mohanty AK, Dilnawaz F, Sahoo SK. Curcumin-encapsulated MePEG/PCL diblock copolymeric micelles: a novel controlled delivery vehicle for cancer therapy. Nanomedicine (Lond). 2010;5(3):433-449.

53. Wu G, Datar RH, Hansen KM, Thundat T, Cote RJ, Majumdar A. Bioassay of prostate-specific antigen (PSA) using microcantilevers. Nat Biotechnol. 2001;19(9):856-860.

54. Tekade RK, Kumar PV, Jain NK. Dendrimers in oncology: an expanding horizon. Chem Rev. 2009;109(1):49-87.

55. Svenson S, Tomalia DA. Dendrimers in biomedical applications reflections on the field. Adv Drug Deliv Rev. 2005;57(15):2106-2129.

56. Tomalia DA. Supramolecular chemistry: fluorine makes a difference. Nat Mater. 2003;2(11):711-712.

57. Choi Y, Thomas T, Kotlyar A, Islam MT, Baker JR Jr. Synthesis and functional evaluation of DNA-assembled polyamidoamine dendrimer clusters for cancer cell-specific targeting. Chem Biol. 2005;12(1): 35-43.

58. $\mathrm{Xu} \mathrm{H}$, Regino CA, Koyama Y, et al. Preparation and preliminary evaluation of a biotin-targeted, lectin-targeted dendrimer-based probe for dual-modality magnetic resonance and fluorescence imaging. Bioconjug Chem. 2007;18(5):1474-1482.

59. Kobayashi H, Brechbiel MW. Dendrimer-based macromolecular MRI contrast agents: characteristics and application. Mol Imaging. 2003; 2(1):1-10.

60. Jiang YH, Emau P, Cairns JS, et al. SPL7013 gel as a topical microbicide for prevention of vaginal transmission of SHIV89.6P in macaques. AIDS Res Hum Retroviruses. 2005;21(3):207-213.

61. Grodzinski P, Silver M, Molnar LK. Nanotechnology for cancer diagnostics: promises and challenges. Expert Rev Mol Diagn. 2006;6(3): 307-318.

62. Nune SK, Gunda P, Thallapally PK, Lin YY, Forrest ML, Berkland CJ. Nanoparticles for biomedical imaging. Expert Opin Drug Deliv. 2009; 6(11):1175-1194.

63. Bianco A, Kostarelos K, Partidos CD, Prato M. Biomedical applications of functionalised carbon nanotubes. Chem Commun (Camb). 2005;5 571-577.

64. Bachilo SM, Strano MS, Kittrell C, Hauge RH, Smalley RE, Weisman RB. Structure-assigned optical spectra of single-walled carbon nanotubes. Science. 2002;298(5602):2361-2366.
65. Pastorin G, Wu W, Wieckowski S, et al. Double functionalization of carbon nanotubes for multimodal drug delivery. Chem Commun (Camb). 2006;11:1182-1184

66. Radomski A, Jurasz P, Alonso-Escolano D, et al. Nanoparticle-induced platelet aggregation and vascular thrombosis. Br J Pharmacol. 2005; 146(6):882-893.

67. Warheit DB, Laurence BR, Reed KL, Roach DH, Reynolds GA, Webb TR. Comparative pulmonary toxicity assessment of single-wall carbon nanotubes in rats. Toxicol Sci. 2004;77(1):117-125.

68. Muller J, Huaux F, Moreau N, et al. Respiratory toxicity of multi-wall carbon nanotubes. Toxicol Appl Pharmacol. 2005;207(3):221-231.

69. De Jong WH, Borm PJ. Drug delivery and nanoparticles: applications and hazards. Int J Nanomedicine. 2008;3(2):133-149.

70. Yin JJ, Lao F, Meng J, et al. Inhibition of tumor growth by endohedral metallofullerenol nanoparticles optimized as reactive oxygen species scavenger. Mol Pharmacol. 2008;74(4):1132-1140.

71. Misra R, Acharya S, Sahoo SK. Cancer nanotechnology: application of nanotechnology in cancer therapy. Drug Discov Today. 2010;15(19-20): $842-850$.

72. Gref R, Minamitake Y, Peracchia MT, Trubetskoy V, Torchilin V, Langer R. Biodegradable long-circulating polymeric nanospheres. Science. 1994;263(5153):1600-1603.

73. Portney NG, Ozkan M. Nano-oncology: drug delivery, imaging, and sensing. Anal Bioanal Chem. 2006;384(3):620-630.

74. Peer D, Karp JM, Hong S, Farokhzad OC, Margalit R, Langer R. Nanocarriers as an emerging platform for cancer therapy. Nat Nanotechnol. 2007;2(12):751-760.

75. Kawasaki ES, Player A. Nanotechnology, nanomedicine, and the development of new, effective therapies for cancer. Nanomedicine. 2005;1(2):101-109.

76. Gref R, Domb A, Quellec P, et al. The controlled intravenous delivery of drugs using PEG-coated sterically stabilized nanospheres. Adv Drug Deliv Rev. 1995;16(2-3):215-233.

77. Deng C, Tian H, Zhang P, Sun J, Chen X, Jing X. Synthesis and characterization of RGD peptide grafted poly(ethylene glycol)b-poly(L-lactide)-b-poly(L-glutamic acid) triblock copolymer. Biomacromolecules. 2006;7(2):590-596.

78. Mosqueira VC, Legrand P, Morgat JL, et al. Biodistribution of longcirculating PEG-grafted nanocapsules in mice: effects of PEG chain length and density. Pharm Res. 2001;18(10):1411-1419.

79. Stolnik S, Dunn SE, Garnett MC, etal. Surface modification of poly(lactideco-glycolide) nanospheres by biodegradable poly(lactide)-poly(ethylene glycol) copolymers. Pharm Res. 1994;11(12):1800-1808.

80. Siddiqui IA, Adhami VM, Bharali DJ, et al. Introducing nanochemoprevention as a novel approach for cancer control: proof of principle with green tea polyphenol epigallocatechin-3-gallate. Cancer Res. 2009;69(5):1712-1716.

81. Shutava TG, Balkundi SS, Vangala P, et al. Layer-by-layer-coated gelatin nanoparticles as a vehicle for delivery of natural polyphenols. ACS Nano. 2009;3(7):1877-1885.

82. Shutava TG, Balkundi SS, Lvov YM. (-)-Epigallocatechin gallate/ gelatin layer-by-layer assembled films and microcapsules. J Colloid Interface Sci. 2009;330(2):276-283.

83. Barras A, Mezzetti A, Richard A, et al. Formulation and characterization of polyphenol-loaded lipid nanocapsules. Int J Pharm. 2009;379(2): 270-277.

84. Zu YG, Yuan S, Zhao XH, Zhang Y, Zhang XN, Jiang R. Preparation, activity and targeting ability evaluation in vitro on folate mediated epigallocatechin-3-gallate albumin nanoparticles. Үао Хие Хие Вао. 2009;44(5):525-531. Chinese.

85. Dube A, Nicolazzo JA, Larson I. Chitosan nanoparticles enhance the intestinal absorption of the green tea catechins (+)-catechin and (-)-epigallocatechin gallate. Eur J Pharm Sci. 2010;41(2):219-225.

86. Han DW, Lee JJ, Jung DY, Park JC, Hyon SH. Development of epigallocatechin gallate-eluting polymeric stent and its physicochemical, biomechanical and biological evaluations. Biomed Mater. 2009;4(4): 44104 . 
87. Italia JL, Datta P, Ankola DD, Kumar MNVR. Nanoparticles enhance per oral bioavailability of poorly available molecules: epigallocatechin gallate nanoparticles ameliorates cyclosporine induced nephrotoxicity in rats at three times lower dose than oral solution. $J$ Biomed Nanotechnol. 2008;4:304-312.

88. Rocha S, Generalov R, Pereira Mdo C, Peres I, Juzenas P, Coelho MA. Epigallocatechin gallate-loaded polysaccharide nanoparticles for prostate cancer chemoprevention. Nanomedicine (Lond). 2011;6(1): 79-87.

89. Singh M, Bhatnagar P, Srivastava AK, Kumar P, Shukla Y, Gupta KC. Enhancement of cancer chemosensitization potential of cisplatin by tea polyphenols poly(lactide-co-glycolide) nanoparticles. J Biomed Nanotechnol. 2011;7(1):202.

90. Hsieh DS, Wang H, Tan SW, et al. The treatment of bladder cancer in a mouse model by epigallocatechin-3-gallate-gold nanoparticles. Biomaterials. 2011;32(30):7633-7640.

91. Aziz MH, Reagan-Shaw S, Wu J, Longley BJ, Ahmad N. Chemoprevention of skin cancer by grape constituent resveratrol: relevance to human disease? FASEB J. 2005;19(9):1193-1195.

92. Aziz MH, Kumar R, Ahmad N. Cancer chemoprevention by resveratrol: in vitro and in vivo studies and the underlying mechanisms (review). Int J Oncol. 2003;23(1):17-28.

93. Bhat KP, Pezzuto JM. Cancer chemopreventive activity of resveratrol. Ann N Y Acad Sci. 2002;957:210-229.

94. Yao Q, Hou SX, He WL, et al. Study on the preparation of resveratrol chitosan nanoparticles with free amino groups on the surface. Zhongguo Zhong Yao Za Zhi. 2006;31(3):205-208. Chinese.

95. Shao J, Li X, Lu X, et al. Enhanced growth inhibition effect of resveratrol incorporated into biodegradable nanoparticles against glioma cells is mediated by the induction of intracellular reactive oxygen species levels. Colloids Surf B Biointerfaces. 2009;72(1):40-47.

96. $\mathrm{Lu} \mathrm{X}, \mathrm{Ji} \mathrm{C}, \mathrm{Xu} \mathrm{H}$, et al. Resveratrol-loaded polymeric micelles protect cells from Abeta-induced oxidative stress. Int J Pharm. 2009;375(1-2): 89-96.

97. Narayanan NK, Nargi D, Randolph C, Narayanan BA. Liposome encapsulation of curcumin and resveratrol in combination reduces prostate cancer incidence in PTEN knockout mice. Int J Cancer. 2009; 125(1):1-8.

98. Kobierski S, Ofori-Kwakye K, Muller RH, Keck CM. Resveratrol nanosuspensions for dermal application - production, characterization, and physical stability. Pharmazie. 2009;64(11):741-747.

99. Teskac K, Kristl J. The evidence for solid lipid nanoparticles mediated cell uptake of resveratrol. Int J Pharm. 2010;390(1):61-69.

100. Yadav VR, Aggarwal BB. Curcumin: A component of the golden spice, targets multiple angiogenic pathways. Cancer Biol Ther. 2011;11(2): 236-241.

101. Tonnesen HH. Solubility, chemical and photochemical stability of curcumin in surfactant solutions. Studies of curcumin and curcuminoids, XXVIII. Pharmazie. 2002;57(12):820-824.

102. Tiyaboonchai W, Tungpradit W, Plianbangchang P. Formulation and characterization of curcuminoids loaded solid lipid nanoparticles. Int J Pharm. 2007;337(1-2):299-306.

103. Bisht S, Feldmann G, Soni S, Ravi R, Karikar C, Maitra A. Polymeric nanoparticle-encapsulated curcumin ("nanocurcumin"): a novel strategy for human cancer therapy. J Nanobiotechnology. 2007;5:3.

104. Sahu A, Bora U, Kasoju N, Goswami P. Synthesis of novel biodegradable and self-assembling methoxy poly(ethylene glycol)-palmitate nanocarrier for curcumin delivery to cancer cells. Acta Biomater. 2008;4(6):1752-1761.

105. Thangapazham RL, Puri A, Tele S, Blumenthal R, Maheshwari RK. Evaluation of a nanotechnology-based carrier for delivery of curcumin in prostate cancer cells. Int J Oncol. 2008;32(5):1119-1123.

106. Das RK, Kasoju N, Bora U. Encapsulation of curcumin in alginatechitosan-pluronic composite nanoparticles for delivery to cancer cells. Nanomedicine. 2010;6(1):153-160.
107. Merrell JG, McLaughlin SW, Tie L, Laurencin CT, Chen AF, Nair LS. Curcumin loaded poly(epsilon-caprolactone) nanofibers: diabetic wound dressing with antioxidant and anti-inflammatory properties. Clin Exp Pharmacol Physiol. 2009;36(12):1149-1156.

108. Li J, Wang Y, Yang C, et al. Polyethylene glycosylated curcumin conjugate inhibits pancreatic cancer cell growth through inactivation of Jab1. Mol Pharmacol. 2009;76(1):81-90.

109. Shaikh J, Ankola DD, Beniwal V, Singh D, Kumar MN. Nanoparticle encapsulation improves oral bioavailability of curcumin by at least 9-fold when compared to curcumin administered with piperine as absorption enhancer. Eur J Pharm Sci. 2009;37(3-4):223-230.

110. Das RK, Kasoju N, Bora U. Encapsulation of curcumin in alginatechitosan-pluronic composite nanoparticles for delivery to cancer cells. Nanomedicine. 2010;6(1):153-160.

111. Anand P, Nair HB, Sung B, et al. Design of curcumin-loaded PLGA nanoparticles formulation with enhanced cellular uptake, and increased bioactivity in vitro and superior bioavailability in vivo. Biochem Pharmacol. 2010;79(3):330-338.

112. Mukerjee A, Vishwanatha JK. Formulation, characterization and evaluation of curcumin-loaded PLGA nanospheres for cancer therapy. Anticancer Res. 2009;29(10):3867-3875.

113. Onoue S, Takahashi H, Kawabata Y, et al. Formulation design and photochemical studies on nanocrystal solid dispersion of curcumin with improved oral bioavailability. J Pharm Sci. 2010;99(4): 1871-1881.

114. Sou K, Oyajobi B, Goins B, Phillips WT, Tsuchida E. Characterization and cytotoxicity of self-organized assemblies of curcumin and amphiphatic poly(ethylene glycol). J Biomed Nanotechnol. 2009; 5(2):202-208.

115. Prajakta D, Ratnesh J, Chandan K, et al. Curcumin loaded pH-sensitive nanoparticles for the treatment of colon cancer. J Biomed Nanotechnol. 2009;5(5):445-455.

116. Yallapu MM, Gupta BK, Jaggi M, Chauhan SC. Fabrication of curcumin encapsulated PLGA nanoparticles for improved therapeutic effects in metastatic cancer cells. J Colloid Interface Sci. 2010;351(1): 19-29.

117. Yallapu MM, Maher DM, Sundram V, Bell MC, Jaggi M, Chauhan SC. Curcumin induces chemo/radio-sensitization in ovarian cancer cells and curcumin nanoparticles inhibit ovarian cancer cell growth. J Ovarian Res. 2010;3:11.

118. Rozzi A, Nardoni C, Corona M, Restuccia MR, Falbo T, Lanzetta G. Weekly regimen of paclitaxel and carboplatin as first-line chemotherapy in elderly patients with stage IIIB-IV non small cell lung cancer (NSCLC): results of a Phase II study. J Chemother. 2011; 22(6):419-423.

119. Gupta SC, Kim JH, Prasad S, Aggarwal BB. Regulation of survival, proliferation, invasion, angiogenesis, and metastasis of tumor cells through modulation of inflammatory pathways by nutraceuticals. Cancer Metastasis Rev. 2010;29(3):405-434.

120. Wu YY, Chang JY, Chao TY. Paclitaxel and carboplatin-induced complete remission in peritoneal carcinomatosis of unknown origin: a report of two cases and review of the literature. Tumori. 2010; 96(2):336-339.

121. George J, Banik NL, Ray SK. Combination of taxol and Bcl-2 siRNA induces apoptosis in human glioblastoma cells and inhibits invasion, angiogenesis and tumour growth. J Cell Mol Med. 2009;13(10): 4205-4218.

122. Fonseca C, Simoes S, Gaspar R. Paclitaxel-loaded PLGA nanoparticles: preparation, physicochemical characterization and in vitro anti-tumoral activity. J Control Release. 2002;83(2):273-286.

123. Feng SS, Mu L, Win KY, Huang G. Nanoparticles of biodegradable polymers for clinical administration of paclitaxel. Curr Med Chem. 2004;11(4):413-424.

124. Onyuksel H, Jeon E, Rubinstein I. Nanomicellar paclitaxel increases cytotoxicity of multidrug resistant breast cancer cells. Cancer Lett. 2009;274(2):327-330 
125. Sahoo SK, Ma W, Labhasetwar V. Efficacy of transferrin-conjugated paclitaxel-loaded nanoparticles in a murine model of prostate cancer. Int J Cancer. 2004;112(2):335-340.

126. Van S, Das SK, Wang X, et al. Synthesis, characterization, and biological evaluation of poly(L-gamma-glutamyl-glutamine)paclitaxel nanoconjugate. Int J Nanomedicine. 2010;5:825-837.

127. Lee AL, Wang Y, Pervaiz S, Fan W, Yang YY. Synergistic anticancer effects achieved by co-delivery of TRAIL and paclitaxel using cationic polymeric micelles. Macromol Biosci. 2011;11(2):296-2307.

128. Bharali DJ, Khalil M, Gurbuz M, Simone TM, Mousa SA. Nanoparticles and cancer therapy: a concise review with emphasis on dendrimers. Int J Nanomedicine. 2009;4(1):1-7.

129. Bharali DJ, Lucey DW, Jayakumar H, Pudavar HE, Prasad PN. Folate-receptor-mediated delivery of InP quantum dots for bioimaging using confocal and two-photon microscopy. J Am Chem Soc. 2005; 127(32):11364-11371.
130. Chatterjee DK, Fong LS, Zhang Y. Nanoparticles in photodynamic therapy: an emerging paradigm. Adv Drug Deliv Rev. 2008;60(15): 1627-1637.

131. Farokhzad OC, Cheng J, Teply BA, et al. Targeted nanoparticle-aptamer bioconjugates for cancer chemotherapy in vivo. Proc Natl Acad Sci U $S$ A. 2006;103(16):6315-6320.

132. Farokhzad OC, Langer R. Impact of nanotechnology on drug delivery. ACS Nano. 2009;3(1):16-20.

133. Zhang L, Gu FX, Chan JM, Wang AZ, Langer RS, Farokhzad OC. Nanoparticles in medicine: therapeutic applications and developments. Clin Pharmacol Ther. 2008;83(5):761-769.

134. Blagosklonny MV. How cancer could be cured by 2015. Cell Cycle. 2005;4(2):269-278.
International Journal of Nanomedicine

\section{Publish your work in this journal}

The International Journal of Nanomedicine is an international, peerreviewed journal focusing on the application of nanotechnology in diagnostics, therapeutics, and drug delivery systems throughout the biomedical field. This journal is indexed on PubMed Central, MedLine, CAS, SciSearch $\AA$, Current Contents ${ }^{\circledR} /$ Clinical Medicine,

\section{Dovepress}

Journal Citation Reports/Science Edition, EMBase, Scopus and the Elsevier Bibliographic databases. The manuscript management system is completely online and includes a very quick and fair peer-review system, which is all easy to use. Visit http://www.dovepress.com/ testimonials.php to read real quotes from published authors.

Submit your manuscript here: http://www.dovepress.com/international-journal-of-nanomedicine-journal 